\title{
Superamphiphobic and Flame-Resistant Cotton Fabrics for Protective Clothing
}

\section{Xiang Liu}

Donghua University https://orcid.org/0000-0002-9396-6482

\section{Qingqing Shao}

Donghua University

\section{Jiqiang Cao}

Donghua University

\section{Zhaoqun Du}

Donghua University

Weidong Yu ( $\sim$ wdyu@dhu.edu.cn)

Donghua University

\section{Research Article}

Keywords: Superamphiphobic, Flame-resistant, Cotton Fabric, Robust, Chemical Repellence

Posted Date: July 23rd, 2021

DOI: https://doi.org/10.21203/rs.3.rs-702994/v1

License: (c) (1) This work is licensed under a Creative Commons Attribution 4.0 International License. Read Full License

Version of Record: A version of this preprint was published at Cellulose on November 13th, 2021. See the published version at https://doi.org/10.1007/s10570-021-04212-y. 


\section{Superamphiphobic and Flame-resistant Cotton Fabrics for Protective

University, Shanghai, 201620, P. R. China.

email:wdyu@dhu.edu.cn

Abstract Superamphiphobic and flame-retardant finishing of cotton fabric can significantly improve its protective properties to expand its applications, such as protective clothing. However, creating such materials is still a challenging issue. Herein, we present a facile strategy to fabricate superamphiphobic and flame-retardant cotton fabric (SFC) via step-by-step dip-coating and spraying technology. Ammonium polyphosphate (APP) endows cotton fabric excellent flame retardancy. The robust coating formed by the polymerization product of ethyl 2-cyanoacrylate (ECA) and $1 \mathrm{H}, 1 \mathrm{H}, 2 \mathrm{H}, 2 \mathrm{H}$-perfluorooctyl trichlorosilane (FOCS) can not only protect APP from being damaged, but also trap air to form "air plastron", which makes SFC have excellent antifouling, chemical repellence and self-cleaning. The resulting SFC exhibited superamphiphobicity and flame retardancy with water contact angle of $161^{\circ}$, oil contact angle of $158^{\circ}$ and LOI of $30 \%$. After UV irradiation, mechanical damage, $180^{\circ} \mathrm{C}$ oven heating and ultrasonic washing, it still maintains excellent hydrophobicity without loss of flame retardancy. This study expands the potential applications of cotton and provides feasible technologies for improving the overall efficiency of cotton.

Keywords Superamphiphobic, Flame-resistant, Cotton Fabric, Robust, Chemical Repellence

\section{Introduction}

Superamphiphobicity is an special surface effect, which are both superhydrophobic and superoleophobic ${ }^{1}$. Tsujii's group ${ }^{2-3}$ first reported on super water and oil repellent surfaces, which has become one of the most popular research topics in recent years. Researchers have designed different superamphiphobic surfaces ${ }^{4-7}$ by combining appropriate surface roughness and materials with a low surface energy. According to reports, long perfluoroalkyl chains are most commonly used to prepare superamphiphobic surfaces. However, in recent years, it has been discovered that materials containing long perfluoroalkyl groups $\left(\mathrm{R}_{\mathrm{fn}}, \mathrm{n} \geq 8\right)$ accumulate in human and animal tissues, and have a long biological half-life, which have been banned in many countries ${ }^{8}$. In view of the above reasons, researchers began to use fluorochemicals with short perfluoroalkyl groups $\left(\mathrm{R}_{\mathrm{fn}}, \leq 6\right)$ to prepare superamphiphobic surfaces ${ }^{9}$. As one of the most advanced surface technologies, superamphiphobic finishing has also been applied to the 
textile field. Fabrics such as $\operatorname{cotton}^{10}$, polyester ${ }^{11-12}$, nylon ${ }^{13}$, and aramid ${ }^{14}$ with superamphiphobicity have been manufactured one after another. Researchers have also studied their applications in the fields of chemical protection ${ }^{15}$, anti-fouling ${ }^{16}$, self-cleaning ${ }^{17}$, and anti-icing 9 .

Cotton is one of the most important natural textile fibers, which is widely used in the textile field, but its flammability and high moisture absorption limit its application in special fields. In order to change these two characteristics together, researchers have proposed some methods for hydrophobic and flameretardant finishing of cotton fabric. For example, people have prepared multifunctional coatings to prepare cotton fabric with superhydrophobic and flame-retardant ${ }^{18-22}$ functions. But the common method is to gradually finish flame-retardant and hydrophobic of the cotton fabric. First, flame-retardant fabric was fabricated by dipping flame retardant (such as ammonium polyphosphate ${ }^{23-25}$, phytic acid ${ }^{26-27}$ or metal oxides ${ }^{28-31}$ ). Then, use a hydrophobic agent (such as silicone ${ }^{20,32-33}$ or fluorosilane ${ }^{29,} 34-35$ ) to perform superhydrophobic finishing on the flame-retardant fabric. Finally, a multi-layered, inside-out composite coating is formed on the surface of the fabric to obtain robust superhydrophobic and flameretardant properties. However, the superhydrophobicity could prevent the flame retardancy of the fabric from being destroyed by water, but it can do nothing in the face of chemical, organic matter or solvents. In addition, the self-cleaning properties of superhydrophobic fabrics are also limited, because most superhydrophobic surfaces are lipophilic, which makes them susceptible to oil stains. Therefore, superamphiphobic and flame-retardant cotton fabric will have better self-cleaning, anti-fouling and chemical resistance, but it have not demonstrated in the research literatures.

In this work, the fabrication of superamphiphobic and flame-retardant cotton fabric (SFC) was fabricated using a step-by-step dip-coating and spraying technology (Fig 1). Ammonium polyphosphate (APP) is an eco-friendly and efficient flame retardant, which significantly improves the flame retardancy of flameretardant cotton fabric (FC). The reactive ethyl 2-cyanoacrylate (ECA, a common instant adhesive) and $1 \mathrm{H}, 1 \mathrm{H}, 2 \mathrm{H}, 2 \mathrm{H}$ - perfluorooctyl trichlorosilane (FOCS) are sprayed onto the FC, and then catalyzed by water vapor to form a robust coating. Benefiting from perfluoroalkyl group of the FOCS, the coating is endowed with a high degree of superamphiphobicity. The PECA formed by ECA polymerization has excellent bonding strength, which ensures the fastness of the combination of cotton fabric and FOCS. As far as we know, there are no similar superamphiphobic and flame-retardant fabric reported before. The preparation method and mechanism of the superamphiphobic flame-retardant coating proposed in this study have certain guiding and reference significance in improving the functionality and bonding fastness of other textile coatings. 


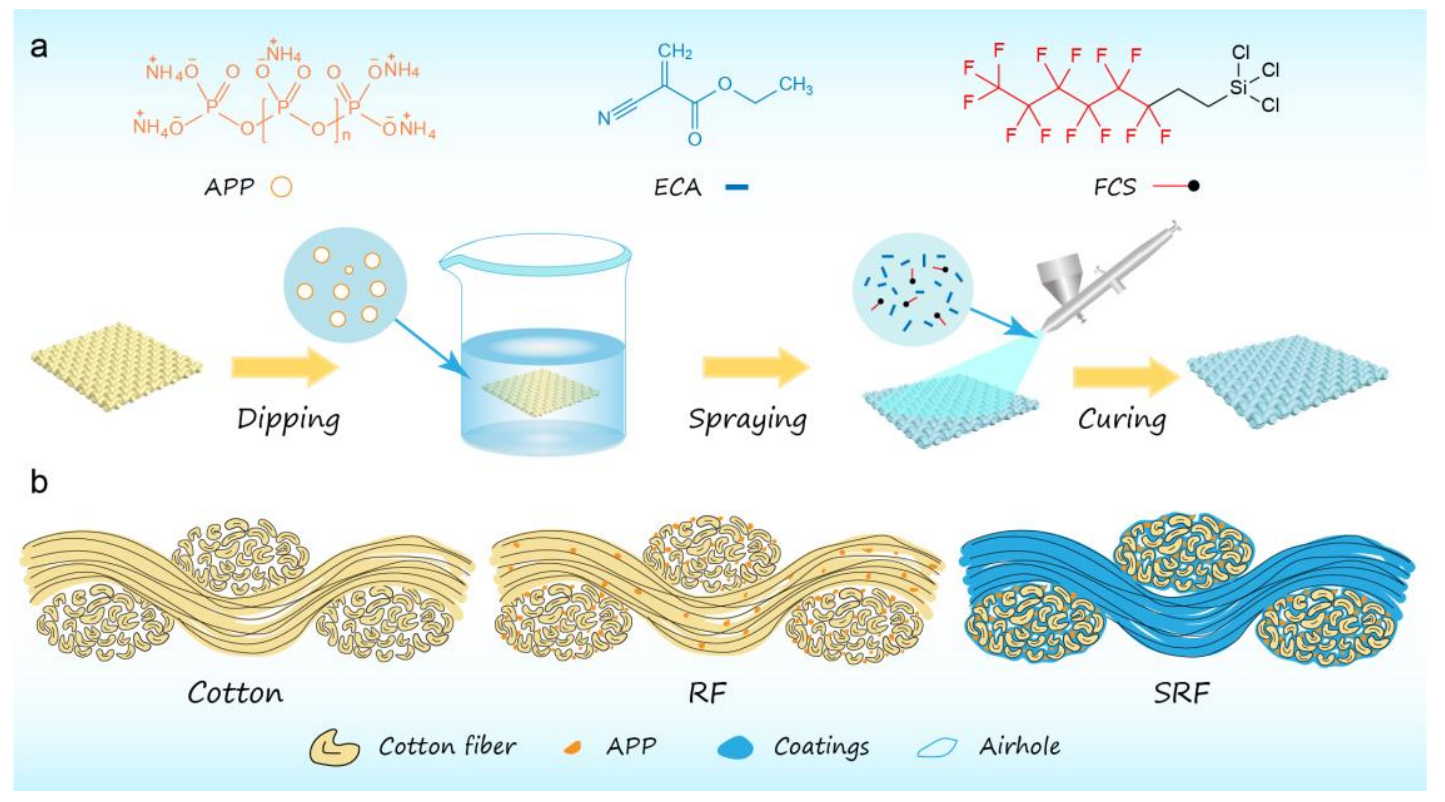

Fig 1. (a). Schematic illustration of the preparation of SFC, and the chemical structure of APP, ECA and FOCS. (b) Schematic illustration of cross section of cotton fabric, FC and SFC.

\section{Experimental section}

\subsection{Materials}

Ammonium polyphosphate (APP) was supplied by Yunnan Tianyao Chemical, $1 H, 1 H, 2 H, 2 H$ perfluorooctyl trichlorosilane (FOCS) was supplied by Energy Chemical. Ethyl 2-cyanoacrylate (ECA) was supplied by Beijing Chemical Works. 1,1-dichloro-1-fluoroethane was supplied by Juhua Chemical Tech. Ethanol, methanol (MT), acetone, $\mathrm{HCl}, \mathrm{NaOH}$, tetrahydrofuran (THF), methyl ethyl ketone (MEK), toluene, $N, N$-dimethylformamide (DMF), and dimethyl sulfoxide (DMSO) were purchased from China National Medicines Co. Ltd. Corn oil was commercially available. All chemicals were used as received without further purification.

\subsection{Fabrication of Superamphiphobic and Flame-resistant Cotton}

The brief procedure to prepare the SFC was schematically illustrated in Fig 1a. The cleaned cotton fabric was immersed into the prepared APP solution $(50 \mathrm{~g} / \mathrm{L})$ for $40 \mathrm{~min}$ and dried at $70^{\circ} \mathrm{C}$ to obtain a flameretardant cotton fabric (FC). And then $0.4 \mathrm{~g}$ of FOCS and $1.6 \mathrm{~g}$ of ECA were added into $4 \mathrm{~g}$ of 1,1 -dichloro1-fluoroethane successively to obtain superamphiphobic coating solution. Subsequently, spray the asprepared solution onto the prepared FC for 2 min to obtain SFC.

\subsection{Characterization}

The element distribution of the fabrics was obtained on an energy dispersive spectrometer (EDS, XMax N20). The surface chemical bonding state of the fabrics was measured by X-ray photoelectron spectroscopy (XPS, Esca lab 250Xi). The Fourier transform infrared (FTIR) spectra of fabrics was 
recorded on a Fourier transform infrared spectrometer (FTIR Spectrum Two). The morphology of fabrics was observed by a scanning electron microscope (SEM DXS-10ACKT). Thermogravimetric analysis (TGA) was performed with a thermogravimetric tester (TGA4000) under a nitrogen atmosphere. The final water contact angle (WCAs) and oil contact angle (OCAs) were obtained by calculating the average value at three different positions of the fabric surface through CA tester (DKSH) under room temperature. The flammability of the fabric was studied by a vertical flammability tester (UL-94). The flame retardancy of the samples was measured by LOI tester (LFY605). The abrasion resistance was investigated by Martindale Abrasion Tester (YG401E) with a load pressure of $12 \mathrm{kPa}$. Ultrasonic cleaner (JAC-4020) was employed to test the washability of the fabrics. The air permeability was measured by an air permeability tester (YG461E). The breaking strength and strain were measured using the testing instrument (Instron 5967).

\section{Results and discussion}

We designed the superamphiphobic and flame-resistant cotton fabric according to the following criteria: (1) the fabric should be highly effective flame retardant; (2) the surface of the fabric should be superamphiphobic to resist harmful substance; (3) the coatings of fabric must be mechanically robust and durable to withstand common damages. As schematically depicted in Fig 1b, FC was first fabricated by dipping the APP aqueous solution, then SFC was obtained by spraying the mixed solution of FOCS and ECA. Briefly, APP is combined with cotton fiber through weak force, which is easy to fall off. After spraying, water vapor in the air is mainly used as a nucleophilic initiator to cause anionic polymerization of ECA to form PECA, and it can also be used as a catalyst to accelerate the polymerization of FOCA to form PFOCA (Fig S1), forming a superamphiphobic coating to protect APP and cotton fibers. The carboxyl group in APP and the hydroxyl group in cellulose and FOCS all contain lone electron pairs are nucleophilic groups. By taking advantage of the binding ability of them to ECA, the coating covalently binds to the fabric Fig 2 . In addition, the huge amount of ester groups and Si-O-Si groups of the coating form strong hydrogen bonds with the hydroxyl groups of the cellulose to ensure that they are firmly fixed on the surface of the fabric. 


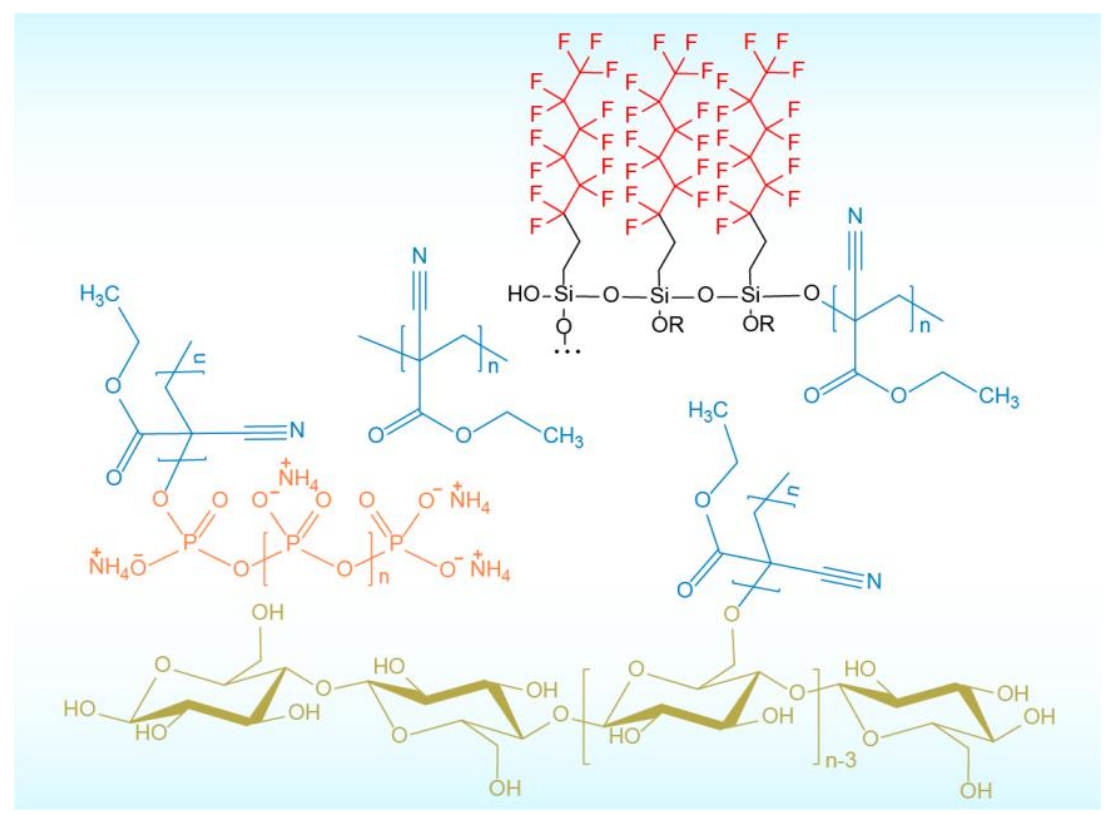

Fig 2. Schematic illustration of chemical bond between coatings and fabric.

\subsection{Chemical Compositions and Surface Morphology}

The chemical composition of the fabric surface plays an important role in its wettability. EDS analysis was carried out to observe the chemical composition of the fabrics. As shown in Fig 3a and Fig S2, after introducing APP on the cotton fabric, the content of $\mathrm{P}$ and $\mathrm{N}$ increased to 4.75 at.\% and 7.25 at. $\%$, while the content of $\mathrm{O}$ and $\mathrm{C}$ changed to 37.87 at.\% and 50.13 at.\%, respectively. Further, after spraying the superamphiphobic coating solution (Fig $\mathbf{3 b}$ ), the percentages of newly introduced $\mathrm{F}$ and $\mathrm{Si}$ elements were 10.91 at. $\%$ and 0.67 at.\%, respectively, while the $\mathrm{P}$ and $\mathrm{N}$ on the surface of the fabric reduce to 2.39 at. $\%$ and 5.05 at. $\%$, respectively, which indicates that the coating formed after spraying covers APP. In

Fig 3c and Fig S3, the EDS mapping images shown that the four elements of F, Si, P and $\mathrm{N}$ were uniformly distributed on the surface of the fiber, suggesting the uniform coverage of flame retardant and low surface energy materials on the cotton fabric.

XPS could not only investigated the composition ratio of chemical elements on the surface, but also verify whether new chemical bonds were formed. As shown in Fig 3d, e, S4 and S5, compared with FC, the $\mathrm{P}$ and $\mathrm{N}$ elements on the surface of SFC decreased from 2.9 at. $\%$ and 4.73 at. $\%$ to 0.21 at. $\%$ and 0.54 at.\%, respectively. However, a large amount of F (52.05 at.\%) and Si (3.43 at.\%) elements have been added. The main reason for the large difference between the F and P elements in the XPS and EDS analysis results of SFC is that the detection depth of the XPS test is about $10 \mathrm{~nm}$, while the EDS is much deeper. This indicates that a large amount of $F$ elements have migrated to the outermost layer of the fabric, thereby forming a low surface energy material to wrap the flame-retardant material, and completely cover the cotton fabric (Fig 3f). To investigate the chemical bond structure in the superamphiphobic coating, we analyzed the high-resolution C1s and Si2p spectra of SFC (Fig $\mathbf{3 g}$, h). The C1s spectrum could be deconvoluted into six peaks centered at 284.58, 285.68, 286.58, 289.58, 292.28 and $294.48 \mathrm{eV}$, which 
corresponded to the $\mathrm{C}$ atoms in $\mathrm{C}-\mathrm{C}, \mathrm{C}-\mathrm{O}, \mathrm{C}=\mathrm{O}, \mathrm{COO}, \mathrm{C}-\mathrm{F}_{2}$ and $\mathrm{C}-\mathrm{F}_{3}$, respectively. The appearance of two new peaks of C-F $\mathrm{F}_{2}$ and $\mathrm{C}-\mathrm{F}_{3}$ verified the successful wrapping of long fluorinated hydrocarbon chains from FOCS, indicating the robust superamphiphobicity of SFC. The Si2p spectrum could be deconvoluted into three peaks centered at 103.88, 102.48 and $101.78 \mathrm{eV}$, corresponding to Si-O-Si, SiO-R and Si-C, respectively. The appearance of the new Si-O-Si peak indicates that the FOCS has undergone a polymerization reaction to form a polymerized FOCS, which is defined as PFOCS.

The fabrics were analyzed by FTIR, and the result was presented in Fig 3i. Compared to cotton, new peaks at 1441 and $1244 \mathrm{~cm}^{-1}$ belong to the $\mathrm{P}=\mathrm{O}$ stretching peak. Those peaks indicate that $\mathrm{FC}$ was successfully fabricated. After the introduction of superamphiphobic coating solution, the peaks at 1212 and $1146 \mathrm{~cm}^{-1}$ appear, corresponding to the stretching vibration modes of $\mathrm{CF}_{3}$ and $\mathrm{CF}_{2}$ respectively. The peak at $1750 \mathrm{~cm}^{-1}$ is ascribed to stretching vibration of mode of -COO- from PECA, and the peak at 1020 $\mathrm{cm}^{-1}$ is assigned to stretching vibration of mode of Si-O-Si from PFOCS.
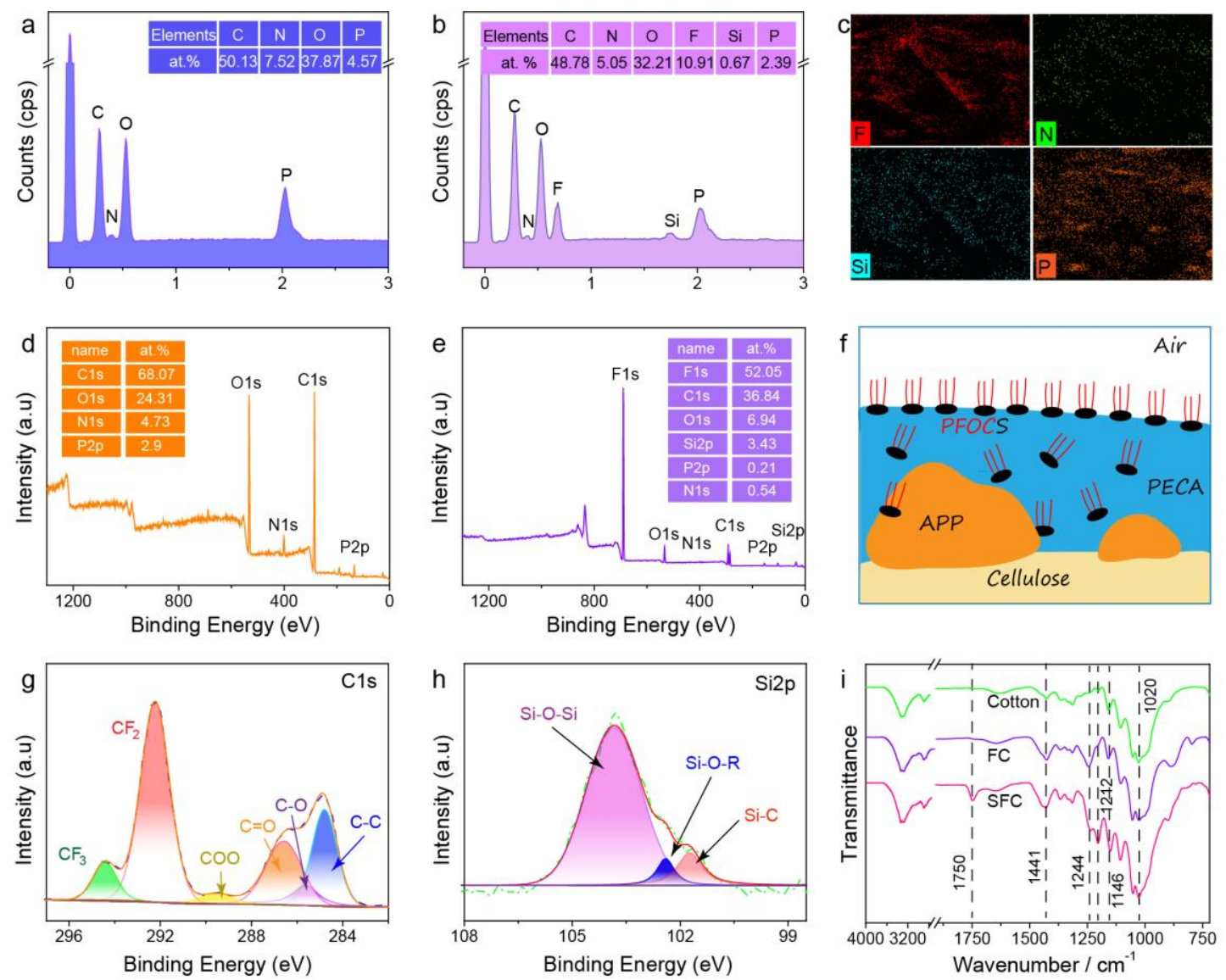

Fig 3. EDS of (a) FC and (b) SFC. (c) EDS mapping images of SFC. XPS spectra of (d) FC and (e) SFC. Schematic illustration (f) of the distribution of flame retardant (APP) adhesive (PECA) and amphiphobic agent (PFOCS) on cotton fabric. High-resolution (g) C 1s and (h) Si 2p spectrum of SFC. FTIR spectra (i) of cotton fabric, FC and SFC.

In addition to the chemical composition of the surface, the roughness of the fabric can enhance the 
wettability of the fabric. The surface morphology of cotton fabric, FC and SFC were characterized by SEM, as shown in Fig $\mathbf{4 a}, \mathbf{b}$, the cotton fibers has a smooth surface and a rod-like structure. Both the WCA and OCA on cotton fabric become $0^{\circ}$ within 5 s and 1s, respectively. In Fig $4 \mathbf{c}, \mathbf{d}$ clearly shows that after flame-retardant finishing, the APP particles attached to cotton fibers and covers the individual cotton fibers. Since APP is water-soluble, the moisture absorption of cotton fabric was obviously enhanced, then the WCA on FC become $0^{\circ}$ within 3s (Fig S6). In contrast, as shown in Fig 4e, f, after spraying, the superamphiphobic coating completely covered the cotton fiber and APP, the WCA and OCA of SFC can reach up to $161^{\circ}$ and $158^{\circ}$, respectively (Fig $\mathbf{4 g \sim i}$ ).
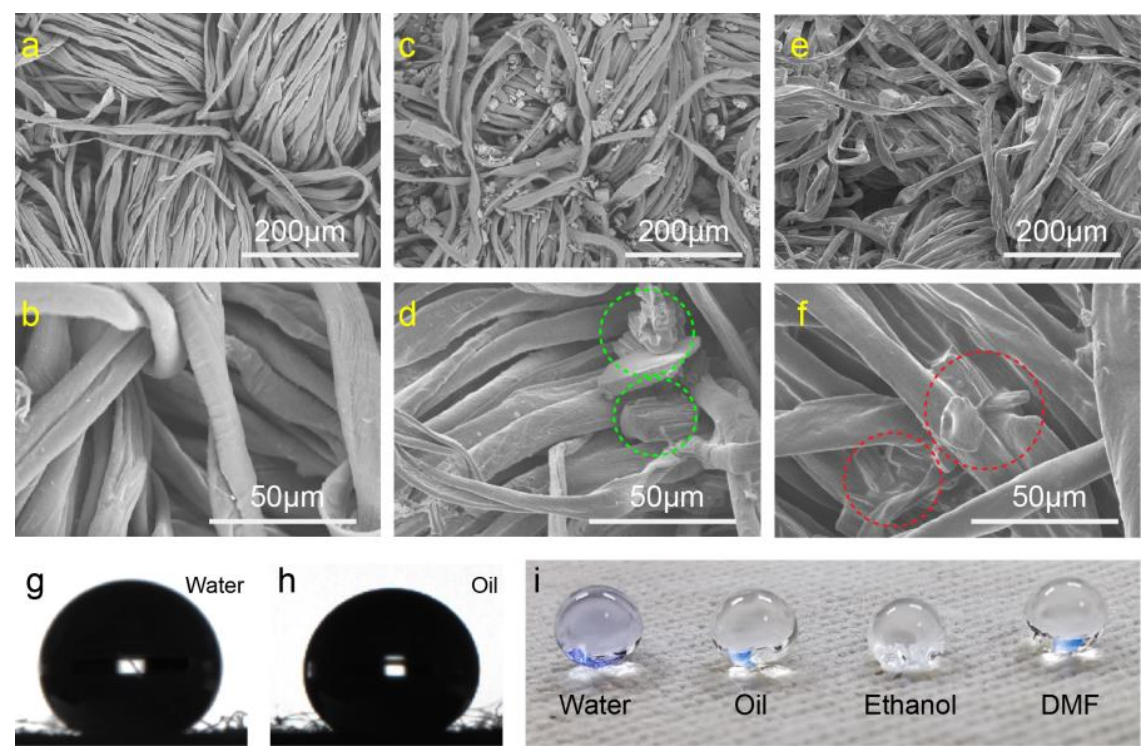

Fig 4. SEM images of (a, b) cotton fabric, (c, d) FC, (e, f) SFC. Photographs of water droplet ( $\sim 5 \mu \mathrm{L})$ contact angle (g) and corn oil droplet ( $\sim 5 \mu \mathrm{L})$ contact angle (h) on SFC. Digital photos of water, oil, ethanol, and DMF on SFC (i).

\subsection{Thermal Performance}

The thermal stability of the pristine cotton fabric, FC and SFC were studied by TG analysis. As shown in Fig 5a. The weight loss of cotton fabric and FC were around $4 \%$ below $150{ }^{\circ} \mathrm{C}$, which caused by evaporating adsorbed water of the cellulose. The first stage of degradation of cotton fabric occurred in the range of $305 \sim 400{ }^{\circ} \mathrm{C}$, and the maximum weight loss was at $380{ }^{\circ} \mathrm{C}$. The reason is the cellulose of cotton decomposed into volatile gases and aliphatic $\mathrm{char}^{36}$. After $405^{\circ} \mathrm{C}$ was the second stage, the weight decreased slowly, and the residual amount at $600{ }^{\circ} \mathrm{C}$ is $19.5 \%$. In this stage, aliphatic char was converted into aromatic structures and released gases such as water, methane, carbon monoxide and carbon dioxide. As shown in Fig $\mathbf{5 b}$, the degradation of FC and SFC mainly occurred in the range of $253 \sim 349^{\circ} \mathrm{C}$, the maximum weight losses were at $326{ }^{\circ} \mathrm{C}, 319^{\circ} \mathrm{C}$ with weight losses of $24.8 \%, 31.1 \%$, respectively. The reasons may be that the polyphosphoric acid produced by the dehydration of APP after about $253{ }^{\circ} \mathrm{C}$ is a strong dehydrating agent, which promoted the dehydration of cellulose and coatings into carbides. As the temperature rises further, the generated non-volatiles such as phosphorus oxides and polyphosphoric 
acid covered the surface of the fabric, and isolated the air to achieve flame retardancy. The residual amount of FC and SFC at $600{ }^{\circ} \mathrm{C}$ were 44.5 and $34.8 \%$. It suggested that APP could improve the thermal stability of cotton and more char residues were formed at high temperature, then the thermal stability of SFC was higher than that of cotton fabric.

\subsection{Flame-resistant Properties}

The flame retardant property of cotton, FC and SFC were investigated by LOI and vertical flammability test. It is generally believed that $\mathrm{LOI}<20 \%$ belongs to flammable materials, and $\mathrm{LOI}>27 \%$ belongs to flame-retardant materials. As shown in Fig $\mathbf{5 c}$, the cotton fabric is flammable materials with the LOI value of $18.2 \%$, and it was completely burnt during the vertical burning test (Fig S7). The afterburn time, afterglow time and residual weight of the cotton fabric were $16 \mathrm{~s}, 21 \mathrm{~s}$ and $0.5 \%$ (Fig 5d), respectively. FC and SFC treated with APP achieved flame retardancy, with LOI values of $31.1 \pm 0.4$ and $30 \pm 0.2 \%$ (Fig 5c), respectively. When the fire source leaves the fabric, the flames on FC and SFC were immediately extinguished, the afterburning time and afterglow time were both 0 , the remaining weight is $37.8 \pm 1.6$ and $27.6 \pm 2.2 \%$, and the char length was $11.6 \pm 0.2$ and $12.4 \pm 0.2 \mathrm{~cm}$, respectively(Fig $\mathbf{5 d}$ ). The char lengths of SFC was less than $13 \mathrm{~cm}$, which met the required maximum char length value (10 15 $\mathrm{cm}$ ) and passed the vertical burning test . The combustion residue was analyzed by SEM (Fig S8), and it was found that there were a large number of bubbles on the surface of the carbon layer, which was similar to the related research results of some previous scholars ${ }^{36}$. It shows that its flame retardant mechanism is that APP is thermally decomposed to produce phosphoric acid to catalyze the dehydration of cotton fibers and PECA and led to char formation. At the same time, it releases inert gas to foam the formed carbon, generating a swollen and porous char layer, which has the effect of shielding heat and oxygen. 

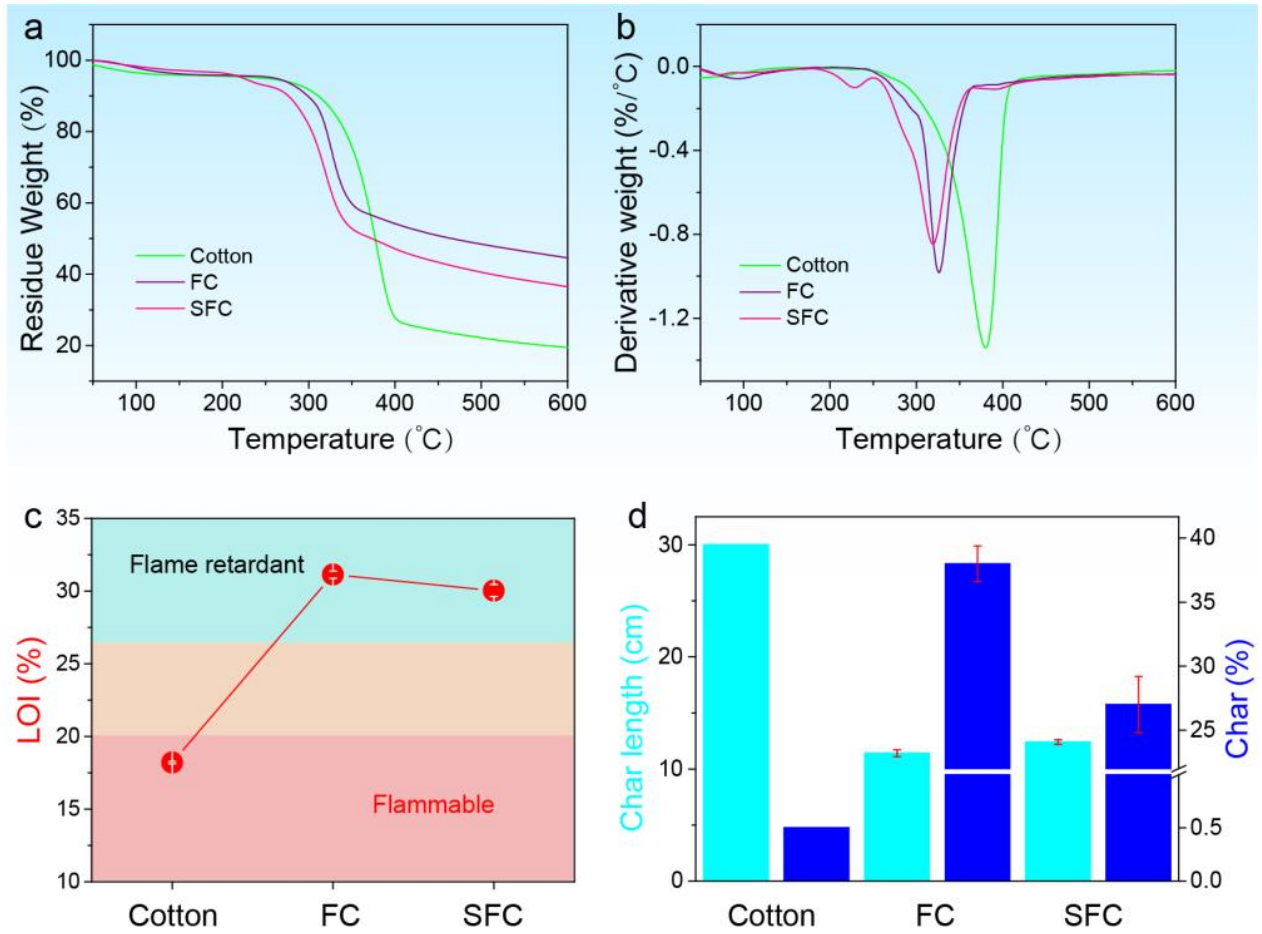

Fig 5. (a) TG and (b) DTG curves of cotton, FC and SFC. (c) LOI, (d) Char lengths and char of cotton, $\mathrm{FC}$ and $\mathrm{SFC}$

\subsection{Self-Cleaning and Anti-Fouling Properties}

As shown in Fig 6a, the self-cleaning test of SFC was carried out using ash as a model pollutant. In this test, the fabrics were fixed on a glass slide with a tilted angle of $\sim 20^{\circ}$, then a layer of ash was sprinkled on the surface of cotton fabric, FC and SFC, respectively. When water and corn oil were continuously dropped onto the polluted surface, ash still stay on the cotton fabric and FC, and the pollution of the fabrics were aggravated (Fig S9). But the ash on the SFC were easily carried away by water and corn oil flow (Fig 6a). Therefore, SFC could protect the fabric from soiling by letting ash roll off under a small force with liquid droplets.

211 Cotton fabric, FC and SFC were separately submerged into different liquids by an external force to test 212 their anti-fouling ability. After SFC was immersed into the liquid, a bright silvery sheen layer can be 213 observed, called an air plastron ${ }^{37}$, which could reduce the interaction between the surface and liquid (Fig 214 6b). Studies have shown that the thickness of air plastron is related to the chemical composition of the 215 material surface and the surface tension of the liquid, while the stability of the air plastron of the surface 216 determined the working effect of the SFC when it is applied in prolonged contact with liquids ${ }^{38}$. After 217 taking them out of the liquids, the surface of the cotton fabric was wetted and soiled (Fig S10), but as 218 illustrated in Fig 6c, SFC remained entirely dry and clean. The above tests shown that SFC has excellent 219 self-cleaning and anti-fouling properties, which can significantly reduce the number of washing cycles. 

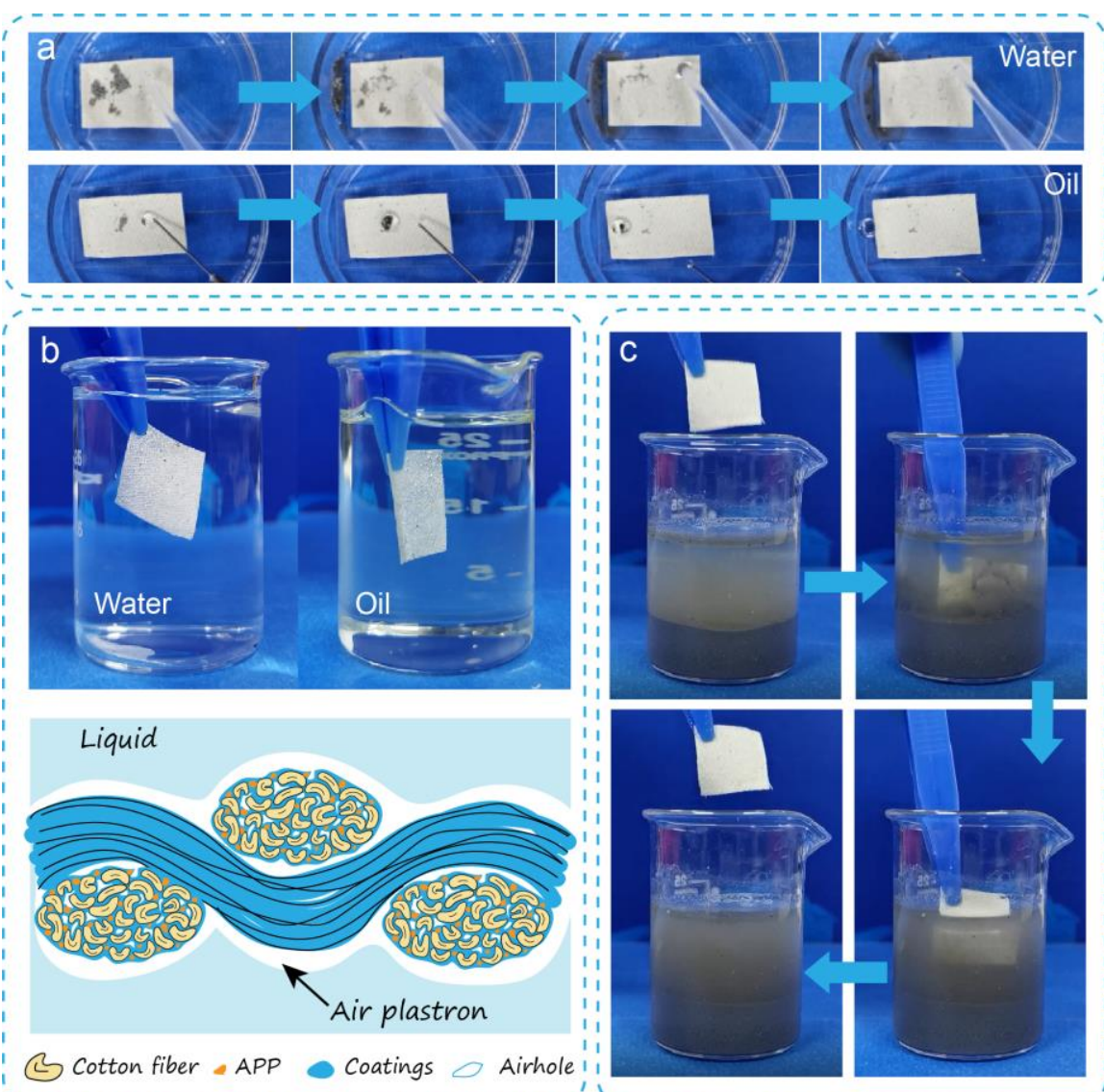

221 Fig 6. Photograph of (a) water and oil self-cleaning property of SFC. The SFC is immersed into (b) water and oil by an external force, showing a silvery sheen layer. Schematic diagram of the air plastron. Photograph of (c) anti-fouling property of SFC.

\subsection{Chemical Protective Properties}

The chemical protective properties of the fabrics were explored via chemical resistance tests to acids, alkalis and organic solvents. For protective clothing, the long-term chemical repellence and stability are key indicators that determine their performance and application feasibility. Fig 7a, $\mathbf{b}$ illustrated the shape change of representative organic solvents droplets (THF and DMF) sitting on the top of the SFC against the contact time. During the test, the shape of the droplets gradually became smaller. After a long time of contact, until the solvents were completely volatilized, the length of the contact interface between the

231 droplets and the SFC did not change, indicating the chemical repellency of SFC was excellent. As shown

232 in Fig 7c, The CAs of methanol, ethanol, DMF, DMSO, acetone, THF, toluene, and MEK all were above

$233130^{\circ}$. In addition, SFC was immersed in $1 \mathrm{M} \mathrm{HCl}$ and $1 \mathrm{M} \mathrm{NaOH}$ respectively, and the contact angle was 234 tested every 25 minutes to prove its chemical stability. As shown in Fig 7d, WCA and OCA of SFC 235 display no significant change, after being immersed in $\mathrm{HCl}$ for 100 minutes. And Fig 7e showed, after 236100 minutes in $\mathrm{NaOH}, \mathrm{CAs}$ of SFC remain over $150^{\circ}$. It can be proved that $\mathrm{SFC}$ can effectively avoid the occurrence of acid and alkali corrosion. 

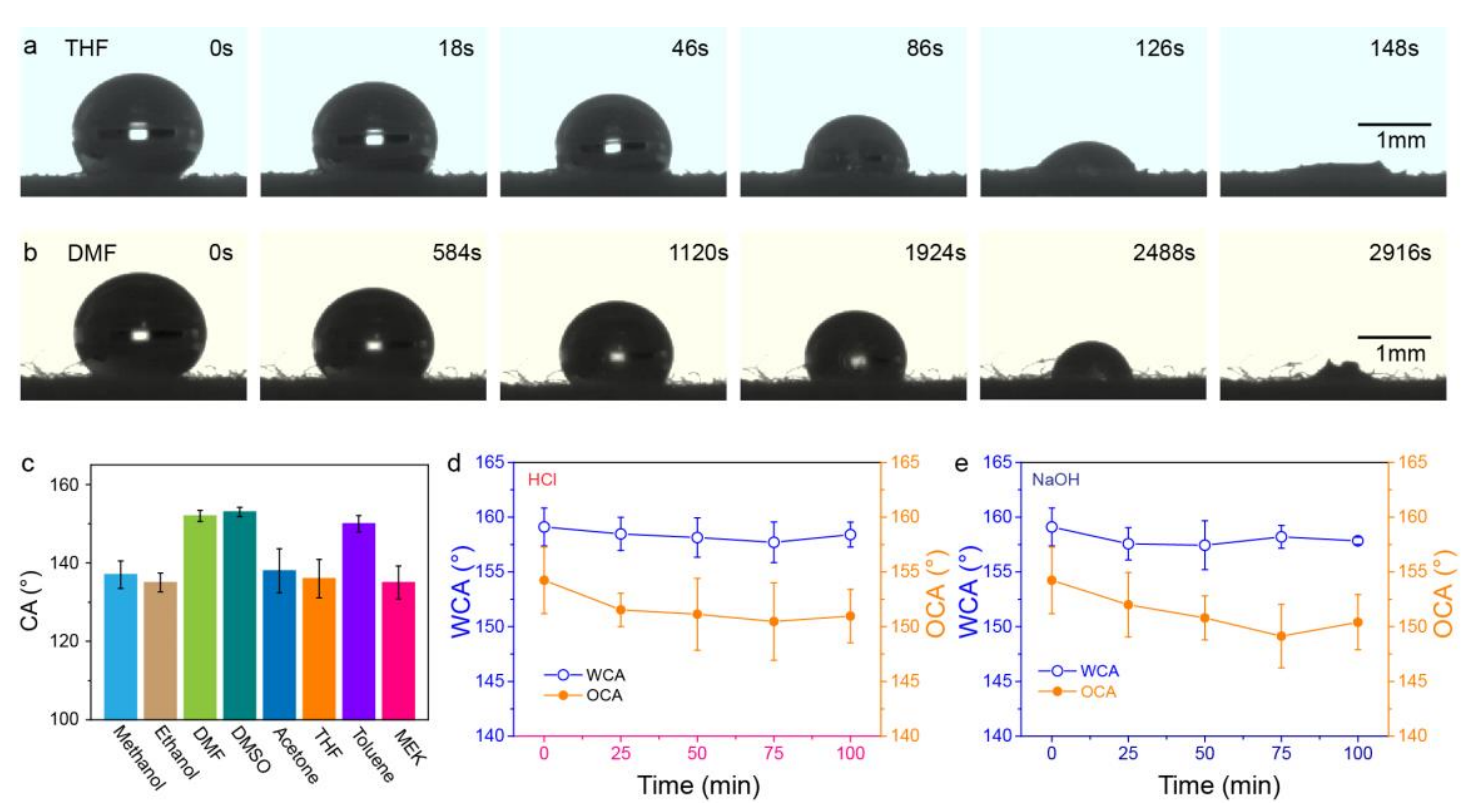

239 Fig 7. Volatilization process of (a) THF and (b) DMF on SAF. CAs of SFC to (c) various organic solvents. CAs and SAs of SAF after immersing in (d) $\mathrm{HCl}$ and (e) $\mathrm{NaOH}$.

3.6 Durability and Robustness

Although introducing superamphiphobic coatings on the surface of cotton fabric could efficiently enhance superamphiphobicity, the robust mechanical performance, water resistance and aging resistance are still a major challenge. Generally, these fluorine-containing materials do not efficiently resist the deformation and abrasive due to that the low surface energy materials did not firmly adhere to the membranes. The mechanical durability of SFC was assessed by abrasion resistance test. As shown in Fig 8a, after being tested 400 cycles, WCAs and OCAs remains $153.1 \pm 2.4^{\circ}$ and $147.6 \pm 2.2^{\circ}$, respectively. The washing resistance of SFC was tested by ultrasonic washing with a frequency of $40 \mathrm{kHz}$. Fig $\mathbf{8 b}$ showed that after $60 \mathrm{~min}$ test, WCAs and OCAs were changed from $159.1 \pm 1.7^{\circ}, 154.2 \pm 3.0^{\circ}$ to $154.5 \pm 1.2^{\circ}, 150.8 \pm 3.6^{\circ}$, respectively.

UV irradiation and heat usually have critical effect on the stability of the fabric and will cause it to age. As shown in Fig 8c, after SFC was exposed to 1000 W UV irradiation for 15 min 4 times, WCAs and OCAs of SFC were maintained above $158^{\circ}$ and $152^{\circ}$, respectively. Thermal endurance test was conducted by heating the $\mathrm{SFC}$ at different temperature for $15 \mathrm{~min}$. After $60 \mathrm{~min}$ heat treatment at $180^{\circ} \mathrm{C}$, WCAs and OCAs remained over $158^{\circ}$ and $152^{\circ}$, which showed no significant change (Fig 8d).

The FC finished with APP alone did not efficiently resist erosion of water or polar solvents because excellent water solubility of APP cannot resist being dissolved by solvents. However, the superamphiphobic coating greatly improves the flame-retardant stability of SFC. The flame retardancy of SFC after 400 cycles of abrasion, $60 \mathrm{~min}$ of ultrasonic washing, $60 \mathrm{~min}$ of UV irradiation and $60 \mathrm{~min}$ of heating, respectively, were investigated by LOI test. As shown in Fig 8e, after testing, the LOI value 
of SFC remained above $29 \%$. And both of them extinguished immediately after leaving the flame, still maintaining excellent flame retardancy.

The results show that the above four tests have no significant effect on the superamphiphobicity and flame retardancy of SFC. According to SEM observation, the test have almost no damage to the structure of the SFC coating, except for abrasion. The damaged SFC was characterized using EDS (Fig 8f). The proportions of C, N, O, F, Si and P elements are 49.75 at.\%, 6.21 at.\%, 30.59 at.\%, 9.54 at.\%, 0.65 at.\% and 3.26 at.\%, respectively. Compared with before abrasion, the ratio of each element hardly changed. And all elements are still evenly distributed on the surface of the fabric(Fig 8g and S11). Furthermore, even SFC was severely damaged by the blade, water droplets and oil droplets remain spherical on seriously worn-out area (Fig $\mathbf{8 h}$ ), and the SFC surfaces remained superamphiphobicity. It can be seen that the superamphiphobic coating has penetrated into the interior of the fabric to protect the internal APP from being damaged. When damaged by external force, as the wear area expands, the outer coating and fibers fall off, and the superamphiphobic coating embedded in the fiber gaps would be exposed, so that the fabric maintain the superamphiphobicity and flame retardancy (Fig 8i).
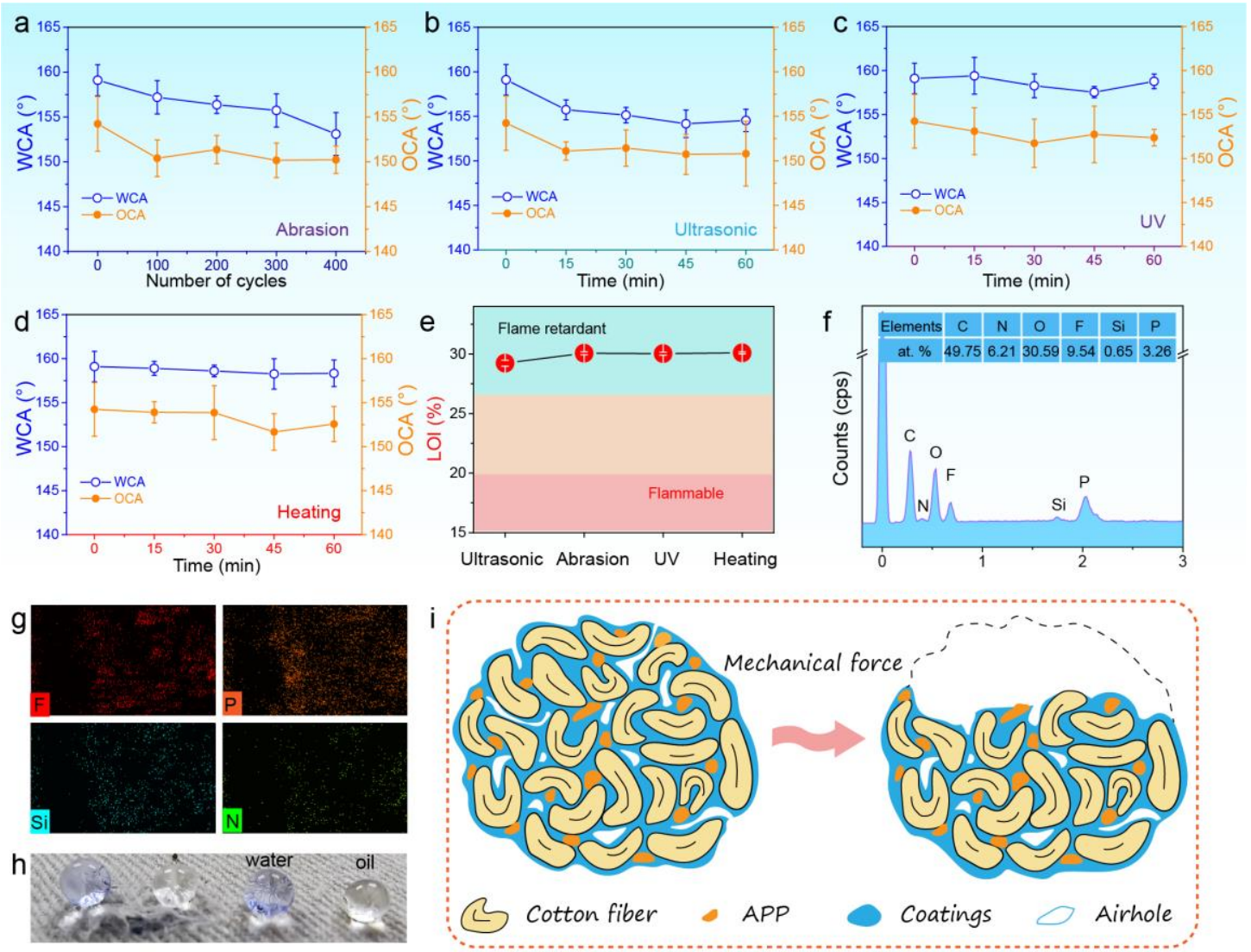

Fig 8. CAs and SAs of SFC under (a) ultrasonic, (b) abrasion, (c)UV irradiation and (d) Heating treatment. (e) LOI\% of SFC after ultrasonic, abrasion, UV irradiation and Heating treatment. EDS (f) of damaged SFC, EDS mapping images (g) of damaged SFC, (h) water and oil droplets on the damaged SFC (i) 
Schematic illustration of cotton fiber shedding and the arrangement of superamphiphobic coating on SFC during mechanical force.

\subsection{Wearability}

The wearing comfort of the fabric ought to be taken into consideration in protective clothing. As shown in Fig 9a, the bending length of SFC was tested using the inclined plane method, which increased from $2.6 \mathrm{~cm}$ to $8.5 \mathrm{~cm}$. We used an intuitive method to prove the moisture permeability of SFC (Fig 9b). First, covering the SFC on the top of the beaker containing hot water, then placing color-changing silica gels on the surface of the SFC, and finally covering it with a large beaker. After 8 minutes, the color-changing silica gels changed from dark blue to pink due to moisture absorption, and the droplet size on the surface of the SFC hardly changed, indicating that SFC has excellent moisture permeability. Fig 9c shows that the air permeability of cotton, FC and SFC were 48.8, 39.9 and $37.2 \mathrm{~mm} / \mathrm{s}$, respectively, with a difference of $11.6 \mathrm{~mm} / \mathrm{s}$ under the pressure difference of $50 \mathrm{~Pa}$. As it increases to $200 \mathrm{~Pa}$, the air permeability increases to $271.1,146$ and $125.9 \mathrm{~mm} / \mathrm{s}$, respectively, and the difference reaches $145.2 \mathrm{~mm} / \mathrm{s}$. This is because the superamphiphobic coating wraps the fibers in the fabric, but does not completely block the gap between them. The breaking strength (Fig 9d) of FC and SFC reduced from 26.3 to 24.2 and 20.5 $\mathrm{MPa}$, while the elongation at break decreased from 22.1 to 19.9 and $16.9 \%$. These results indicate that the SFC still has satisfactory flexibility air permeability and mechanical behavior for protective clothing.
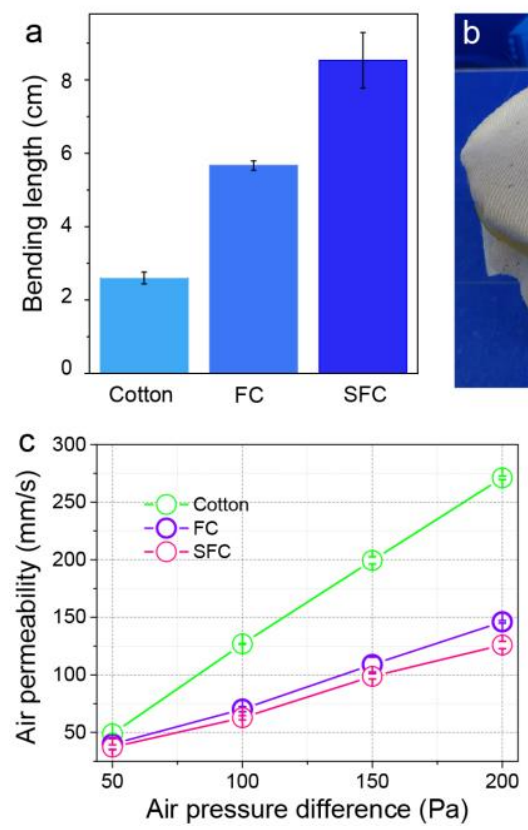
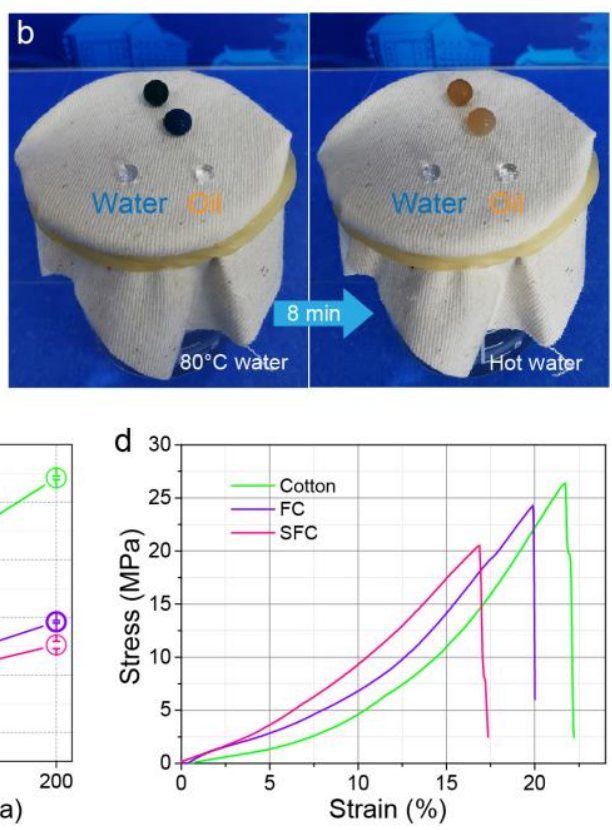

Fig 9. (a) Bending length of cotton, FC and SFC. (b) Measurement method of moisture permeability. (c) Air permeability of cotton, FC and SFC in different air pressure. (d)Typical breaking stress-strain curves of cotton, FC and SFC.

\section{Conclusions}


we have demonstrated a simple and feasible strategy for preparation of SFC through a step-by-step dipcoating and spraying technology. FOCS and ECA were coated onto the surface of FC covered with APP to construct a highly amphiphobic surface. As a result, SFC achieved integrated properties with WCA of $161^{\circ}$, OCA of $158^{\circ}$, LOI of $30 \%$ and good wearability, which can provide a high level of protection as well as comfort. Furthermore, the superamphiphobicity also has endowed SFC with excellent selfcleaning, anti-Fouling and chemical protective properties. SFC still showed superamphiphobicity and flame-retardance after 400 cycles of abrasion, 60 cycles of ultrasonic washing, 60 min of UV irradiation $(1000 \mathrm{~W})$, and $60 \mathrm{~min}$ of heat treatment $\left(180^{\circ} \mathrm{C}\right)$, which lays a foundation for its large-scale applications. We believe that SFC is very promising candidate for the next generation materials of high-end protective clothing that can be used in extreme condition for life jackets, chemical protective clothing, firefighting suits, and outer packaging of smart devices.

This work was supported by the National Key R\&D Program of China (2016YFC0802802). National Natural Science Foundation of China (51963020)

\section{Reference}

317 (1) Chu, Z.; Seeger, S. Superamphiphobic surfaces. Chem. Soc. Rev. 2014, 43, 2784-2798.

(2) Tsujii, K.; Yamamoto, T.; Onda, T.; Shibuichi, S. Super oil - repellent surfaces. Angewandte Chemie

(3) Shibuichi, S.; Yamamoto, T.; Onda, T.; Tsujii, K. Super water-and oil-repellent surfaces resulting from fractal structure. J. Colloid Interface Sci. 1998, 208, 287-294.

(4) Tuteja, A.; Choi, W.; Ma, M.; Mabry, J. M.; Mazzella, S. A.; Rutledge, G. C.; McKinley, G. H.; Cohen, R. E. Designing superoleophobic surfaces. Science 2007, 318, 1618-1622.

(5) Deng, X.; Mammen, L.; Butt, H.-J.; Vollmer, D. Candle soot as a template for a transparent robust superamphiphobic coating. Science 2012, 335, 67-70.

(6) Liu, H.; Wang, Y.; Huang, J.; Chen, Z.; Chen, G.; Lai, Y. Bioinspired surfaces with superamphiphobic properties: concepts, synthesis, and applications. Adv. Funct. Mater. 2018, $28,1707415$. shielding. Journal of the American Chemical Society 2013, 135, 578-581. breathable fibrous membranes with short perfluorobutyl chains for eco-friendly protective textiles. $A C S$ Appl. Mater. Interfaces 2018, 10, 30887-30894. 
(9) Moiz, A.; Padhye, R.; Wang, X. Durable superomniphobic surface on cotton fabrics via coating of silicone rubber and fluoropolymers. Coatings 2018, 8, 104.

(10) Wang, H.; Zhou, H.; Gestos, A.; Fang, J.; Lin, T. Robust, superamphiphobic fabric with multiple self-healing ability against both physical and chemical damages. ACS Appl. Mater. Interfaces 2013, 5, 10221-10226.

(11) Zhou, X.; Sun, S.; Zhang, C.; Wang, X. Y.; Li, Y. L.; Jiang, Y. Facile fabrication of durable superamphiphobic PET fabrics. Journal of Coatings Technology and Research 2019, 1-8.

(12) Li, G.; Lee, H. J.; Michielsen, S. Design of abrasion resistant super-antiwetting nylon surfaces. New J. Chem. 2017, 41, 13593-13599.

(13) Siddig, E. A. A.; Xu, Y.; He, T.; Gao, M.; Yang, B.; Wang, T.; Zhang, J.. Plasma-induced graft polymerization on the surface of aramid fabrics with improved omniphobicity and washing durability. Plasma Science and Technology 2020, 22, 055503.

(14) Yeerken, T.; Yu, W.; Feng, J.; Xia, Q.; Liu, H. Durable superamphiphobic aramid fabrics modified by PTFE and FAS for chemical protective clothing. Prog. Org. Coat. 2019, 135, 41-50.

(15) Guo, X.-J.; Xue, C.-H.; Jia, S.-T.; Ma, J.-Z. Mechanically durable superamphiphobic surfaces via synergistic hydrophobization and fluorination. Chem. Eng. J. 2017, 320, 330-341.

(16) Luo, G.; Wen, L.; Yang, K.; Li, X.; Xu, S.; Pi, P.; Wen, X. Robust and durable fluorinated 8MAPOSS-based superamphiphobic fabrics with buoyancy boost and drag reduction. Chem. Eng. J. 2020, $383,123125$.

(17) Pan, S.; Guo, R.; Björnmalm, M.; Richardson, J. J.; Li, L.; Peng, C.; Bertleff-Zieschang, N.; Xu, W.; Jiang, J.; Caruso, F. Coatings super-repellent to ultralow surface tension liquids. Nature materials 2018, 17, 1040-1047.

(18) Chen, T.; Hong, J.; Peng, C.; Chen, G.; Yuan, C.; Xu, Y.; Zeng, B.; Dai, L. Superhydrophobic and flame retardant cotton modified with DOPO and fluorine-silicon-containing crosslinked polymer. Carbohydr. Polym. 2019, 208, 14-21.

(19) Sezer Hicyilmaz, A.; Altin, Y.; Bedeloglu, A. Polyimide - coated fabrics with multifunctional properties: Flame retardant, UV protective, and water proof. J. Appl. Polym. Sci. 2019, 136, 47616.

(20) Abdelrahman, M. S.; Khattab, T. A. Development of One - Step Water - Repellent and Flame Retardant Finishes for Cotton. ChemistrySelect 2019, 4, 3811-3816.

(21) Li, S.; Huang, S.; Xu, F.; Zhao, T.; Zhang, F.; Zhang, G. Imparting superhydrophobicity and flame retardancy simultaneously on cotton fabrics. Cellulose 2020, 1-17. 
(22) Liu, J.; Dong, C.; Zhang, Z.; Kong, D.; Sun, H.; Lu, Z. Multifunctional flame-retarded and hydrophobic cotton fabrics modified with a cyclic phosphorus/polysiloxane copolymer. Cellulose 2020, 27, 3531-3549.

(23) Lin, D.; Zeng, X.; Li, H.; Lai, X.; Wu, T. One-pot fabrication of superhydrophobic and flameretardant coatings on cotton fabrics via sol-gel reaction. J. Colloid Interface Sci. 2019, 533, 198-206.

(24) Xue, C.-H.; Zhang, L.; Wei, P.; Jia, S.-T. Fabrication of superhydrophobic cotton textiles with flame retardancy. Cellulose 2016, 23, 1471-1480.

(25) Li, S.; Lin, X.; Li, Z.; Ren, X. Hybrid organic-inorganic hydrophobic and intumescent flameretardant coating for cotton fabrics. Composites Communications 2019, 14, 15-20.

(26) Nie, S.; Jin, D.; Yang, J.-n.; Dai, G.; Luo, Y. Fabrication of environmentally-benign flame retardant cotton fabrics with hydrophobicity by a facile chemical modification. Cellulose 2019, 26, 5147-5158.

(27) Liu, L.; Huang, Z.; Pan, Y.; Wang, X.; Song, L.; Hu, Y. Finishing of cotton fabrics by multi-layered coatings to improve their flame retardancy and water repellency. Cellulose 2018, 25, 4791-4803.

(28) Wang, B.; Peng, S.; Wang, Y.; Li, X.; Zhang, K.; Liu, C. A non-fluorine method for preparing multifunctional robust superhydrophobic coating with applications in photocatalysis, flame retardance, and oil-water separation. New J. Chem. 2019, 43, 7471-7481.

(29) Zhang, M.; Zang, D.; Shi, J.; Gao, Z.; Wang, C.; Li, J. Superhydrophobic cotton textile with robust composite film and flame retardancy. RSC advances 2015, 5, 67780-67786.

(30) Ambekar, R. S.; Deshmukh, A.; Suarez-Villagran, M. Y.; Das, R.; Pal, V.; Dey, S.; Miller Jr, J. H.; Machado, L. D.; Kumbhakar, P.; Tiwary, C. S. 2D Hexagonal Boron Nitride-Coated Cotton Fabric with Self-Extinguishing Property. ACS Appl. Mater. Interfaces 2020, 12, 45274-45280.

(31) Wang, W.; Wang, J.; Wang, X.; Wang, S.; Liu, X.; Qi, P.; Li, H.; Sun, J.; Tang, W.; Zhang, S. Improving flame retardancy and self-cleaning performance of cotton fabric via a coating of in-situ growing layered double hydroxides (LDHs) on polydopamine. Prog. Org. Coat. 2020, 149, 105930.

(32) Nabipour, H.; Wang, X.; Song, L.; Hu, Y. Hydrophobic and flame-retardant finishing of cotton fabrics for water-oil separation. Cellulose 2020, 27, 4145-4159.

(33) Suryaprabha, T.; Sethuraman, M. G. Fabrication of superhydrophobic and enhanced flame-retardant coatings over cotton fabric. Cellulose 2018, 25, 3151-3161.

(34) Chen, S.; Li, X.; Li, Y.; Sun, J. Intumescent flame-retardant and self-healing superhydrophobic coatings on cotton fabric. ACS nano 2015, 9, 4070-4076.

(35) Lin, D.; Zeng, X.; Li, H.; Lai, X. Facile fabrication of superhydrophobic and flame-retardant 
coatings on cotton fabrics via layer-by-layer assembly. Cellulose 2018, 25, 3135-3149.

396 (36) Gao, D.; Zhang, Y.; Lyu, B.; Wang, P.; Ma, J. Nanocomposite based on poly (acrylic acid)/attapulgite towards flame retardant of cotton fabrics. Carbohydr. Polym. 2019, 206, 245-253.

(37) Shirtcliffe, N. J.; McHale, G.; Newton, M. I.; Perry, C. C.; Pyatt, F. B. Plastron properties of a superhydrophobic surface. Appl. Phys. Lett. 2006, 89, 104106.

400 (38) Liu, G.; Xia, H.; Zhang, W.; Lang, L.; Geng, H.; Song, L.; Niu, Y. Photocatalytic Superamphiphobic 


\section{Supplementary Files}

This is a list of supplementary files associated with this preprint. Click to download.

- SupplementaryInformation.pdf 